\title{
Prototipe Power Supply Gate Driver untuk Multilevel Inverter dengan Menggunakan Flyback Converter Multi Output
}

\author{
Novie Ayub Windarko', Akhmad Puryanto ${ }^{2}$, Rachma Prilian Eviningsih ${ }^{3}$, Moh. \\ Zaenal Efendi ${ }^{4}$, Eka Prasetyono ${ }^{5}$, Bambang Sumantri ${ }^{6}$ \\ 1,2,3,4,5,6 Departemen Teknik Elektro, \\ Politeknik Elektronika Negeri Surabaya \\ 12ayub@pens.ac.id, 2akhmad.puryanto97@gmail.com, ${ }^{3}$ rachmaevin@pens.ac.id, ${ }^{4}$ zen@ \\ pens.ac.id, ${ }^{5}$ eka@pens.ac.id, 6 bambang@pens.ac.id
}

\begin{abstract}
Abstrak
Dengan perkembangan konverter elektronika daya, kebutuhan untuk memperkecil ukuran dan keandalan semakin meningkat. Dengan meningkatnya frekuensi switching pada konverter, maka $\mathrm{d} v / \mathrm{d} t$ yang tinggi dapat menyebabkan kesalahan dalam turn-on ataupun turn-off switching devices. Masalah-masalah tersebut dapat diatasi dengan menerapkan tegangan bias negatif untuk melakukan turn-off switching devices. Makalah ini mengusulkan prototipe power supply gate driver yang dikhususkan untuk Multi Level Inverter (MLI). Sebuah prototipe power supply gate driver yang menggunakan satu unit konverter flyback dengan multi output untuk tegangan bias positif dan negatif, serta terisolasi galvanis sebanyak switching devices MLI. Dengan menggunakan topologi dasar flyback maka konverter ini memiliki isolasi galvanis melalui trafo frekuensi tinggi. Dari hasil eksperimen proses switching bisa berubah dari kondisi dari on menuju off dan dari off menuju on bisa berjalan secara sempurna.
\end{abstract}

Kata kunci: power supply, gate driver, MLI, flyback, multioutput.

\begin{abstract}
As the power electronic converters develop rapidly, the need of compactness and reliability increases accordingly. Higher switching frequency may leads to faulty when turning on and off the switching devices. These problems can be solved by applying negative bias voltage when turning off switching devices. This study proposes gate driver power supply prototype specially designed for Multi Level Inverter (MLI). This prototype used a flyback converter with multioutput for positive and negative bias voltage, and also isolated by galvanic as many as the MLI switching devices. By using flyback topology, the converter has galvanic isolation through high frequency transformer. The experiments show that the switching process fromon-to-off and from-off-to-on works perfectly.
\end{abstract}

Keywords: power supply, gate driver, MLI, flyback, multioutput.

\section{Pendahuluan}

Dalam beberapa dekade ini, konverter daya dc ke ac, atau biasa disebut inverter, memainkan peran penting dalam variable frequency drives, air conditioning, uninterruptible power supplies, induction heating, high-voltage dc power transmission, penggerak kendaraan listrik, filter aktif, dan pemanfaatan sumber daya energi terbarukan [1]. Berdasarkan sifat 
bentuk gelombang output, inverter dapat diklasifikasikan sebagai: square wave inverters, quasi-square wave inverters, two-level pulse width modulation (PWM) inverters, and multilevel inverters (MLI) [2].

Dalam beberapa tahun terakhir, multilevel inverter telah menjadi semakin menarik karena sesuai untuk aplikasi tegangan tinggi, efisiensi tinggi dan EMI yang rendah, sesuai untuk aplikasi daya besar, tegangan output distorsi rendah dan respon dinamik yang baik[3]. Efisiensi tinggi dan EMI yang rendah dapat dihasilkan karena switching devices turn-on dan turn-off hanya satu kali per siklus. MLI didesain untuk menghasilkan daya yang besar meskipun dengan menggunakan switching devices semikonduktor dengan rating tegangan rendah.

Prinsip kerja MLI adalah melakukan konversi daya dengan menghasilkan tegangan tangga yang menyerupai gelombang sinus. MLI menggunakan beberapa sumber tegangan DC yang dijumlahkan untuk menghasilkan tegangan AC. Kapasitor, baterai, dan sumber tegangan energi terbarukan dapat digunakan sebagai sumber tegangan DC pada MLI. Semakin banyak sumber tegangan DC, maka tegangan output mendekati mendekati bentuk gelombang sinusoidal. Oleh sebab itu rugi daya switching menjadi rendah dan komponen penyaklaran tidak mengalami stress tegangan yang tinggi [4]. Namun, Multilevel inverter memiliki beberapa kelemahan. Salah satu kelemahan khusus adalah banyaknya kekuatan switching semikonduktor diperlukan. Meski tingkat komponen switching devices bertegangan rendah dapat digunakan dalam Multilevel inverter, namun masing-masing switching devices membutuhkan gate driver. Hal ini dapat menyebabkan keseluruhan sistem menjadi lebih mahal dan kompleks. Untuk implementasi praktis, sangat penting untuk mengurangi jumlah switching devices dan gate driver. Lebih jauh telah diteliti beberapa aplikasi MLI baru dengan pengoperasian yang efisien, ukuran yang lebih kecil, gate driver lebih sedikit serta biaya rendah[5]-[6].

Beberapa peneliti tertarik untuk mengembangkan power supply untuk gate driver pada inverter. Khususnya untuk MLI, sebagian besar switching devices pada posisi mengambang, sehingga jumlah power supply yang dibutuhkan cukup banyak. Hal ini menimbulkan kerumitan tersendiri pada rangkaian.

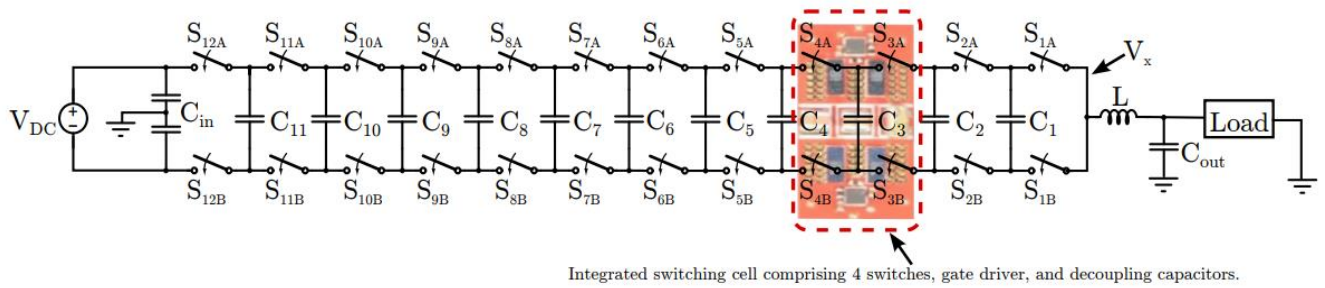

Gambar 1. Inverter 13 level dengan power supply gate driver per 4 switching devices

Beberapa peneliti menggunakan prinsip Bootstrap charge pump untuk power supply gate driver pada MLI [7]. Power supply bertegangan rendah bisa dari kapasitor dc link. Namun topologi ini dapat menyebabkan permasalahan EMI dan asimetri dari sisi pandang topologi maupun pengoperasian [8]. Sebagian peneliti menggunakan DC-DC Converter On-chip [9]-[10] sebagai solusi yang efektif, ditunjukkan pada Gambar 1. Namun penggunaan On-Chip menyebabkan biaya yang mahal [11].

Dengan perkembangan konverter elektronika daya, kebutuhan untuk memperkecil ukuran dan keandalan semakin meningkat. Pada konverter yang menggunakan induktor atau transformator, dimensi komponen magnetik biasanya berbanding terbalik dengan 
frekuensi switching. Dengan meningkatnya frekuensi switching, maka $\mathrm{d} v / \mathrm{d} t$ yang tinggi dapat menyebabkan kesalahan dalam turn-on ataupun turn-off switching devices. Masalahmasalah tersebut dapat diatasi dengan menerapkan bias negatif untuk melakukan turn-off switching devices [12].

Pada makalah ini dipaparkan tentang prototype power supply gate driver yang dikhususkan untuk MLI. Prototype menggunakan satu unit konverter flyback dengan multi output untuk bias tegangan positif dan negatif, serta terisolasi galvanis sebanyak switching devices MLI. Prototype ini diharapkan bisa berbentuk rangkaian sederhana, namun tetap bisa berfungsi dengan baik.

\section{Metode}

\subsection{Rangkaian Flyback Converter Multi Output}

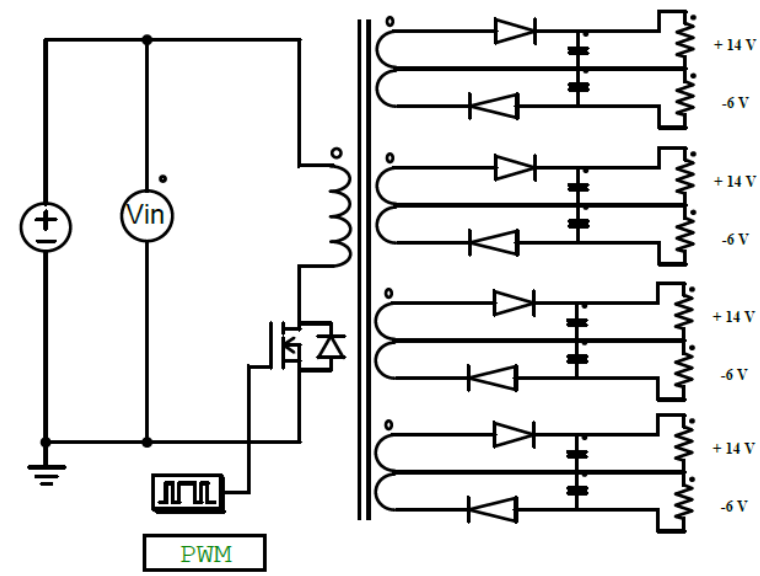

Gambar 2. Flyback multioutput dengan tegangan bias positif dan negatif

Gambar 2 menunjukkan konverter yang diusulkan untuk memenuhi kebutuhan power supply gate driver. Sesuai dengan kebutuhan pada MLI, konverter tersebut menyediakan multioutput dan menyediakan tegangan bias positif dan negatif. Konverter yang digunakan adalah tipe flyback. Dengan menggunakan topologi dasar flyback maka konverter ini memiliki isolasi galvanis melalui trafo frekuensi tinggi.

\subsection{Prinsip Kerja Flyback Converter Multi Output}

Flyback terdiri dari trafo isolasi frekuensi tinggi antara input dan output, satu switching devices di sisi primer, diode penyearah pada sisi sekunder dan filter $C$ pada sisi sekunder dan tersier, seperti ditunjukkan Gambar 3. Prinsip kerja Flyback adalah memanfaatkan induktansi magnetic dari trafo sebagai penyimpan energi pada saat konversi daya. Prinsip kerja dianalisis berdasarkan switching devices tertutup dan terbuka.

Saat switching devices tertutup, sumber tegangan $V_{s}$ akan paralel dengan tegangan kumparan primer $V_{1}$. Pada sisi primer trafo arus akan mengalir ke Lm dan kumparan $\mathrm{N}_{1}$. Sehingga:

$$
v_{1}=V_{s}=L_{m} \frac{d i_{L m}}{d t}
$$


Bila dinyatakan dalam perubahan arus pada Lm maka:

$$
\frac{d i_{L m}}{d t}=\frac{\Delta i_{L m}}{\Delta t}=\frac{\Delta i_{L m}}{D T}=\frac{V_{S}}{L m}
$$

di mana DT adalah periode atau durasi waktu selama switching devices tertutup.

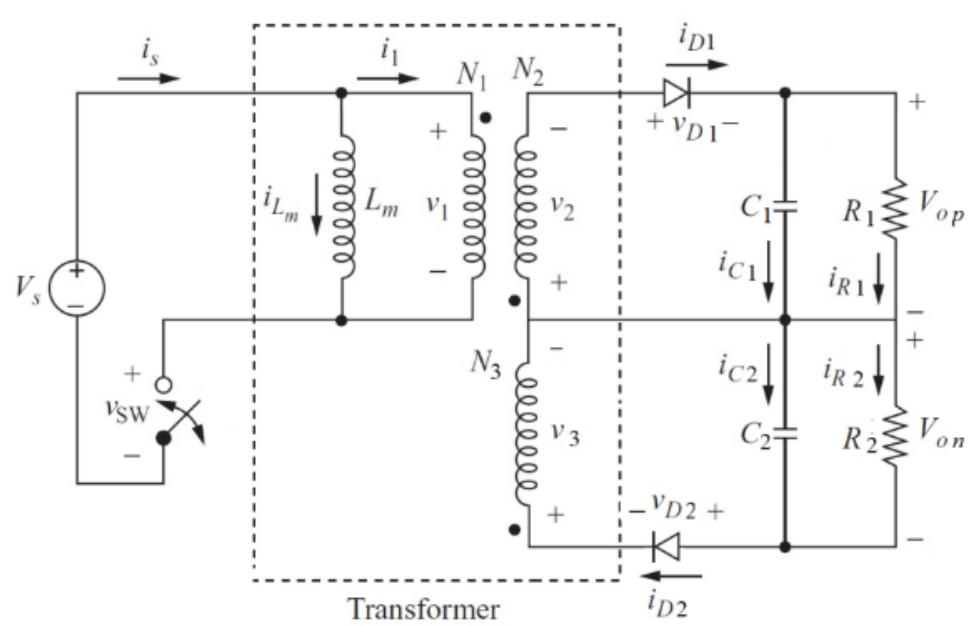

Gambar 3. Analisa rangkaian flyback multioutput

Arus yang mengalir ke Lm akan disimpan sebagai energi. Maka perubahan arus selama switching devices tertutup sebesar:

$$
\left(\Delta i_{L m}\right)_{\text {closed }}=\frac{V s D T}{L m}
$$

Pada sisi sekunder dan tersier arus tidak dapat mengalir karena arah arus bias mundur terhadap diode $\mathrm{D}_{1}$ dan $\mathrm{D}_{2}$. Pada kondisi ini beban $\mathrm{R}_{1}$ dan $\mathrm{R}_{2}$ disuplai arus dari $\mathrm{C}_{1}$ dan $\mathrm{C}_{2}$. Di mana:

$$
\begin{gathered}
v_{2}=v_{1}\left(\frac{N 2}{N 1}\right)=V s\left(\frac{N 2}{N 1}\right) \\
v_{3}=v_{1}\left(\frac{N 3}{N 1}\right)=V s\left(\frac{N 3}{N 1}\right) \\
V d 1=-V o p-V s\left(\frac{N 2}{N 1}\right)<0 \\
V d 2=-V o n-V s\left(\frac{N 3}{N 1}\right)<0 \\
i 1=i 2=i 3=0
\end{gathered}
$$

Di mana $V_{d 1}$ dan $V_{d 2}$ adalah tegangan pada diode $\mathrm{D}_{1}$ dan $\mathrm{D}_{2}$. Vop adalah tegangan bias positif, dan Von adalah tegangan bias negatif.

Saat switching devices terbuka, pada sisi primer trafo, arus akan mengalir dari Lm ke kumparan $\mathrm{N}_{1}$. Arus yang mengalir di kumparan $\mathrm{N}_{1}$ akan transfer ke kumparan sekunder $N_{2}$ dan kumparan tersier $\mathrm{N}_{3}$. Diode $\mathrm{D}_{1}$ dan $\mathrm{D}_{2}$ mendapatkan arus bias maju, sehingga arus 
Prototipe Power Supply Gate Driver untuk Multilevel Inverter dengan Menggunakan Flyback Converter Multi Output

Novie Ayub Windarko, Akhmad Puryanto, Rachma Prilian Eviningsih, Moh. Zaenal Efendi, Eka Prasetyono, Bambang Sumantri

mengalir ke $C_{1}, C_{2}, R_{1}$ dan $R_{2}$. Dengan mengasumsikan tegangan output $V_{o p}$ dan $V_{\text {on }}$ tetap konstan, maka tegangan kumparan sekunder $\mathrm{N}_{2}$ dan kumparan tersier $\mathrm{N}_{3}$ menjadi sama dengan $V_{o p}$ dan $V_{o n}$

$$
\begin{aligned}
& v_{2}=-V_{o p} \\
& v_{3}=-V_{o n}
\end{aligned}
$$

Tegangan ini akan berimbas ke tegangan kumparan primer yang paralel terhadap Lm, sehingga:

atau

$$
\begin{gathered}
v_{1}=-V_{o p}\left(\frac{N 1}{N 2}\right) \\
v_{1}=-V_{o n}\left(\frac{N 1}{N 3}\right) \\
L m \frac{d i_{L m}}{d t}=v_{1}=-V_{o p}\left(\frac{N 1}{N 2}\right) \\
L m \frac{d i_{L m}}{d t}=v_{1}=-V_{o n}\left(\frac{N 1}{N 3}\right)
\end{gathered}
$$

Bila dinyatakan dalam perubahan arus pada $\mathrm{Lm}$ maka:

$$
\frac{d i_{L m}}{d t}=\frac{\Delta i_{L m}}{\Delta t}=\frac{\Delta i_{L m}}{(1-D) T}=-\frac{V_{o p}}{L m}\left(\frac{N 1}{N 2}\right)
$$

atau

$$
\frac{d i_{L m}}{d t}=\frac{\Delta i_{L m}}{\Delta t}=\frac{\Delta i_{L m}}{(1-D) T}=-\frac{V_{o n}}{L m}\left(\frac{N 1}{N 3}\right)
$$

Di mana (1-D)T adalah periode/durasi waktu selama switching devices terbuka.

Arus Lm yang mengalir merupakan pelepasan energi. Maka perubahan arus Lm selama switching devices terbuka sebesar:

$$
\left(\Delta i_{L m}\right)_{\text {open }}=\frac{-V o p(1-D) T}{L m}\left(\frac{N 1}{N 2}\right)
$$

atau

$$
\left(\Delta i_{L m}\right)_{\text {open }}=\frac{-\operatorname{Von}(1-D) T}{L m}\left(\frac{N 1}{N 3}\right)
$$

Dalam satu periode total arus yang mengalir pada Lm adalah nol.

$$
\left(\Delta i_{\text {Lm }}\right)_{\text {open }}+\left(\Delta i_{\text {Lm }}\right)_{\text {closed }}=0
$$

Sehingga tegangan output dapat dinyatakan dengan:

atau

$$
V o p=V S\left(\frac{D}{1-D}\right)\left(\frac{N 2}{N 1}\right)
$$

$$
\operatorname{Von}=\operatorname{Vs}\left(\frac{D}{1-D}\right)\left(\frac{N 3}{N 1}\right)
$$




\section{Hasil Dan Pembahasan}

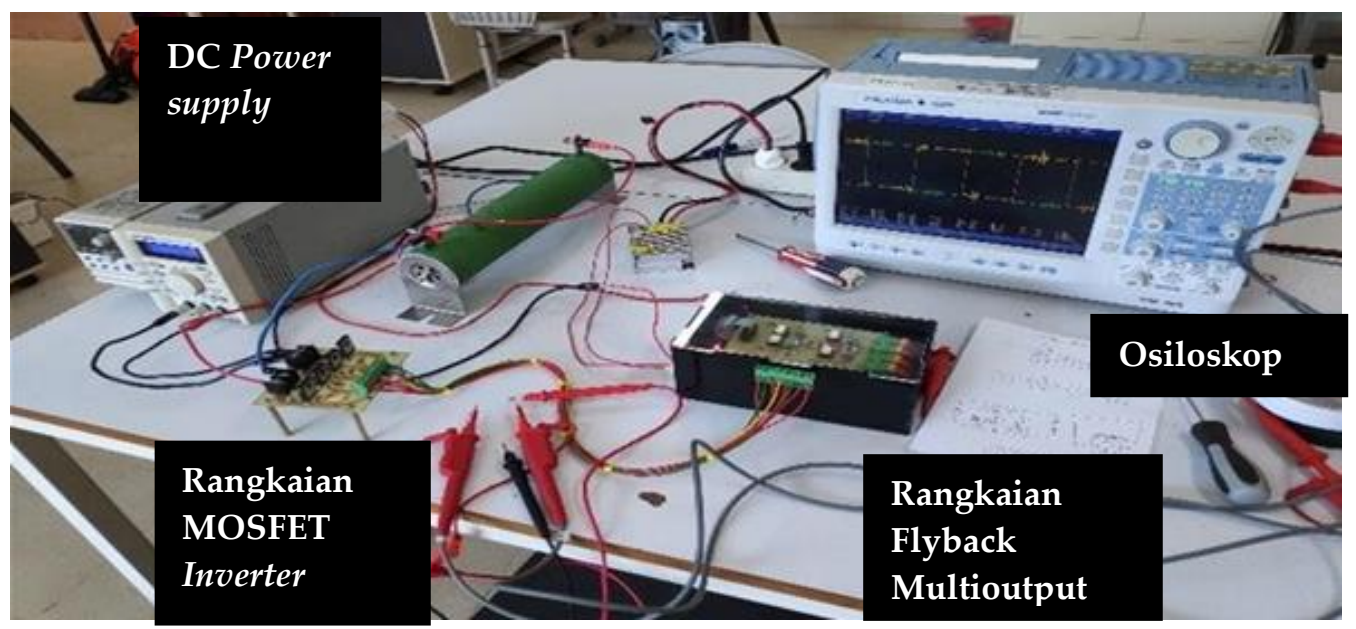

Gambar 4. Rangkaian pengujian alat beserta alat ukur dan pendukung

Pengujian konverter yang diusulkan tampak pada Gambar 4. Rangkaian flyback multioutput diujikan pada rangkaian inverter yang terdiri dari MOSFET yang beroperasi sebagai switching devices low side dan high-side. Pada pengujian ini respon tegangan dan arus direkam dengan osiloskop DL850 Yokogawa.

Konverter didesain untuk menghasil tegangan bias positif sebesar $14 \mathrm{~V}$ dan tegangan bias negatif sebesar -6 V. Dengan desain untuk digunakan pada MLI tiga tingkat [13], maka konverter didesain dengan 4 output dengan sepasang tegangan bias positif dan negatif untuk setiap output. Pada Gambar 5 nampak konverter yang menggunakan satu inti trafo frekuensi tinggi dengan kumparan sekunder 4 buah, di mana kumparan untuk tegangan bias positif dan negatif dalam satu kumparan dengan centre tap. Hasil pengukuran trafo dengan menggunakan LCR meter ditunjukkan pada Tabel 1. Flyback dioperasikan dengan frekuensi switching sebesar $40 \mathrm{kHz}$.

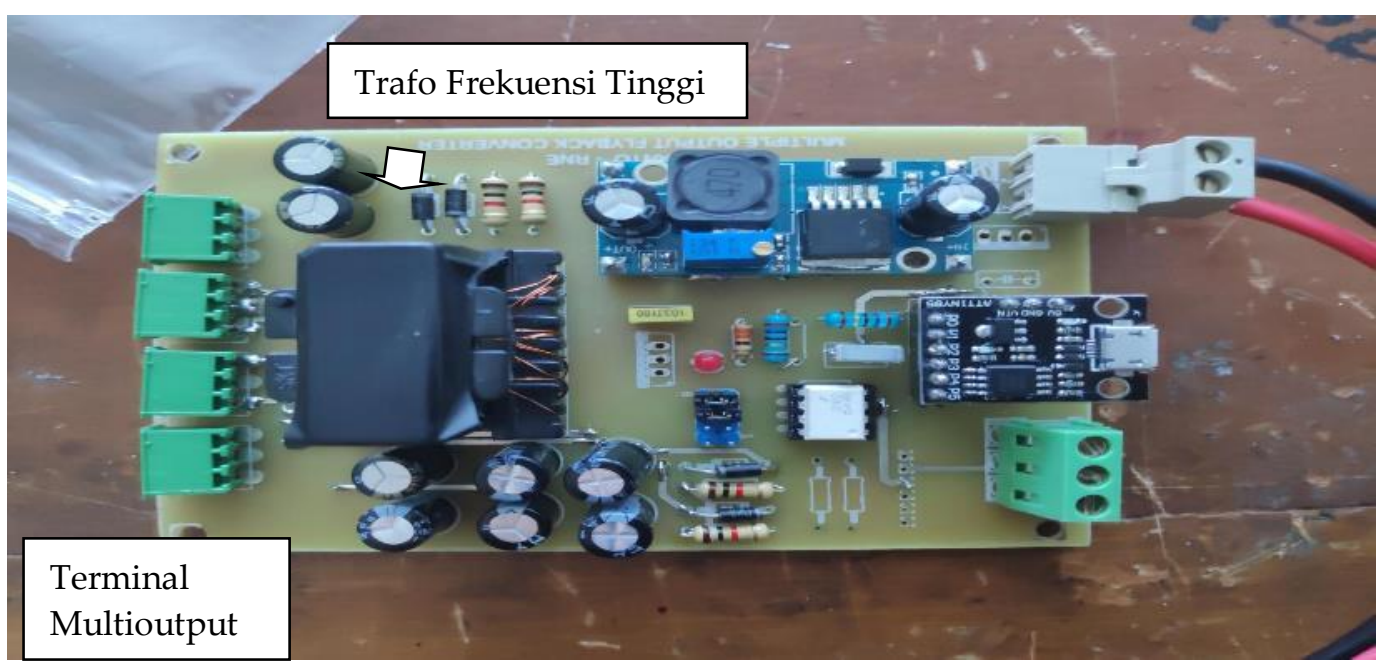

Gambar 5. Rangkaian Flyback multioutput 
Prototipe Power Supply Gate Driver untuk Multilevel Inverter dengan Menggunakan Flyback Converter Multi Output

Novie Ayub Windarko, Akhmad Puryanto, Rachma Prilian Eviningsih, Moh. Zaenal Efendi, Eka Prasetyono, Bambang Sumantri

Tabel 1. Spesifikasi trafo frekuensi tinggi pada flyback

\begin{tabular}{|c|c|}
\hline Kumparan Trafo & Nilai \\
\hline Primer & $\mathrm{N}_{1}=42, \mathrm{R}=0,5 \Omega, \mathrm{Lm}=2,23 \mathrm{mH}$ \\
\hline Sekunder 1 & $\begin{array}{l}N_{2}=27, R_{-} N_{2}=0,6 \Omega, L_{-} N_{2}=2,14 \mathrm{mH} \\
N_{3}=12, R_{-} N_{3}=0,4 \Omega, L_{-} N_{3}=0,22 \mathrm{mH}\end{array}$ \\
\hline Sekunder 2 & $\begin{array}{l}\mathrm{N}_{2}=27, \mathrm{R} \_\mathrm{N}_{2}=0,6 \Omega, \mathrm{L}_{-} \mathrm{N}_{2}=2,03 \mathrm{mH} \\
\mathrm{N}_{3}=12, \mathrm{R} \_\mathrm{N}_{3}=0,4 \Omega, \mathrm{L}_{-} \mathrm{N}_{3}=0,22 \mathrm{mH}\end{array}$ \\
\hline Sekunder 3 & $\begin{array}{l}\mathrm{N}_{2}=27, \mathrm{R} \_\mathrm{N}_{2}=0,6 \Omega, \mathrm{L}_{-} \mathrm{N}_{2}=2,15 \mathrm{mH} \\
\mathrm{N}_{3}=12, \mathrm{R} \_\mathrm{N}_{3}=0,4 \Omega, \mathrm{L}_{-} \mathrm{N}_{3}=0,23 \mathrm{mH}\end{array}$ \\
\hline Sekunder 4 & $\begin{array}{l}\mathrm{N}_{2}=27, \mathrm{R} \_\mathrm{N}_{2}=0,6 \Omega, \mathrm{L}_{-} \mathrm{N}_{2}=2,05 \mathrm{mH} \\
\mathrm{N}_{3}=12, \mathrm{R} \mathrm{N}_{3}=0,4 \Omega, \mathrm{L} \mathrm{N}_{3}=0,20 \mathrm{mH}\end{array}$ \\
\hline
\end{tabular}

Gambar 6 menunjukkan respon output konverter flyback yang diamati selama 0,5 detik. Osiloskop dioperasikan dengan V/div $=5$ volt/div dan time/div sebesar $50 \mathrm{~ms} /$ div. Respon tegangan bias positif pada Gambar 6a menunjukkan kondisi steady state pada tegagan 14,68 volt converter memerlukan waktu rise time sebesar $28,01 \mathrm{~ms}$ dengan overshoot sebesar $3,28 \%$. Sedangkan pada Gambar $6 \mathrm{~b}$ menunjukkan respon tegangan bias negatif steady state pada tegangan $-6 \mathrm{k} 53 \mathrm{~V}$, rise time sebesar $29 \mathrm{k} 80 \mathrm{~ms}$ dengan overshoot sebesar 0,70\%.

Pada Gambar 7, konverter diujikan untuk menyuplai daya gate driver pada inverter. Inverter dioperasikan dengan frekuensi switching $10 \mathrm{KHz}$ menggunakan modulasi $P W M$ dengan duty 50\%. Gambar 7a menunjukkan respon tegangan $V g s$ dan Gambar $7 \mathrm{~b}$ respon tegangan $V g s$ pada MOSFET dengan pengoperasian osiloskop time/div=20us/div dan $\mathrm{V} / \mathrm{div}=5 \mathrm{~V} / \mathrm{div}$. Respon MOSFET menunjukkan tidak ada permasalahan dalam proses turnon dan turn-off pada switching device.

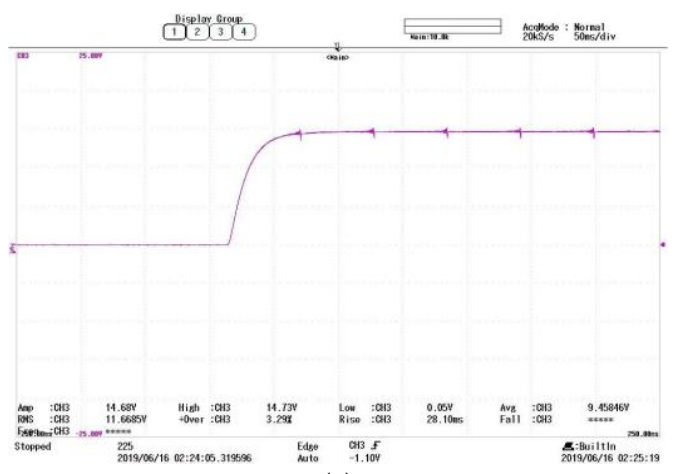

(a)

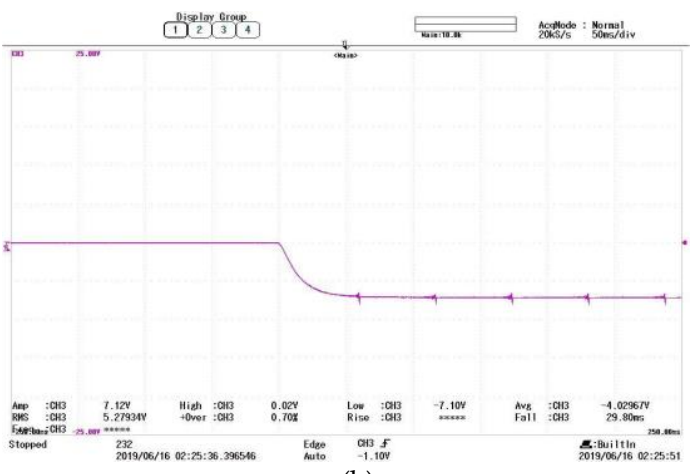

(b)

Gambar 6. Respon tegangan: (a) bias positif Vop dan (b) bias negatif Von 

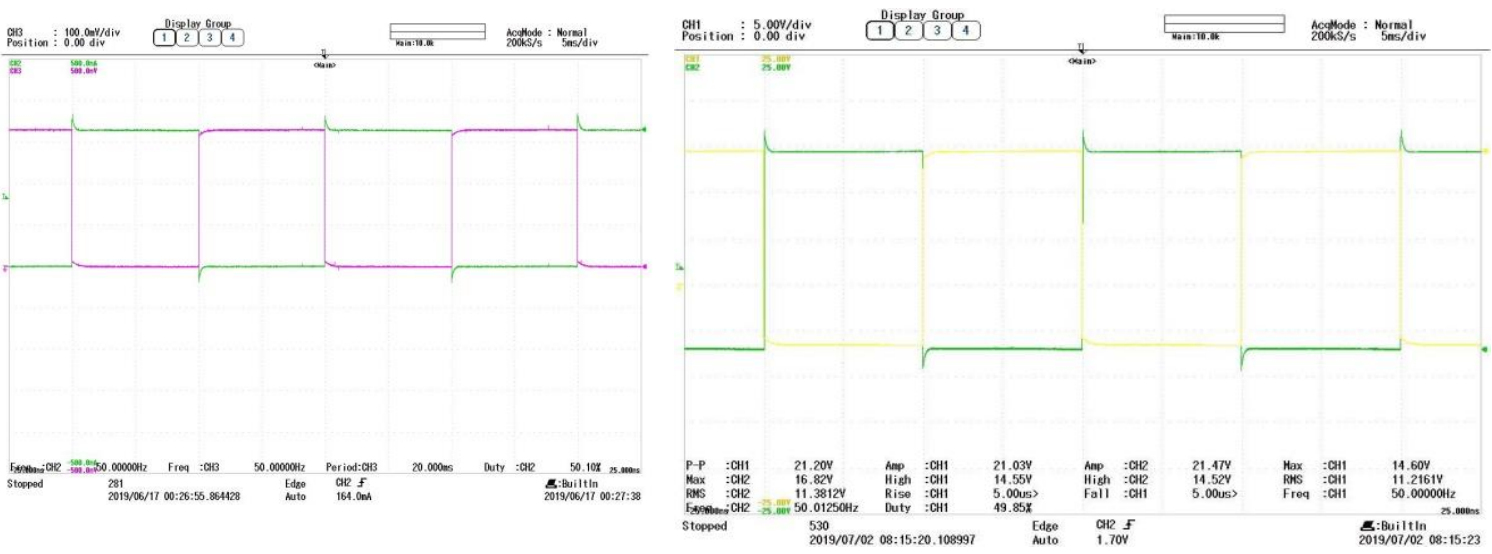

(a)

(b)

Gambar 7. Pengujian gate driver: (a) respon pada $V g s$ dan (b) Vds MOSFET

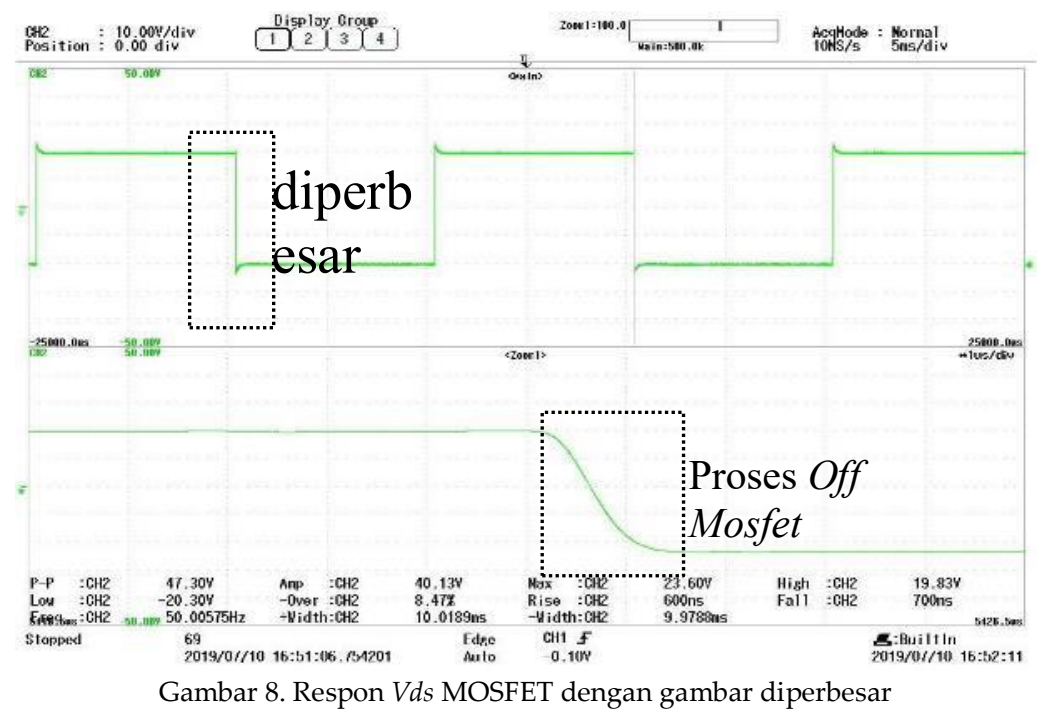

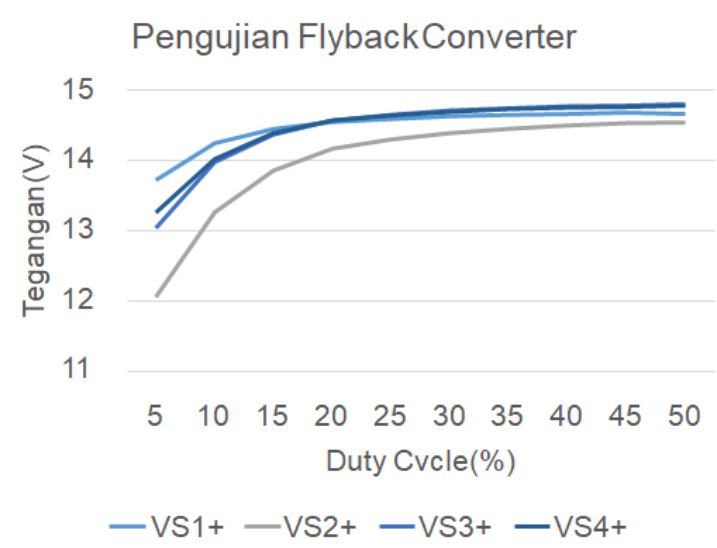

(a)

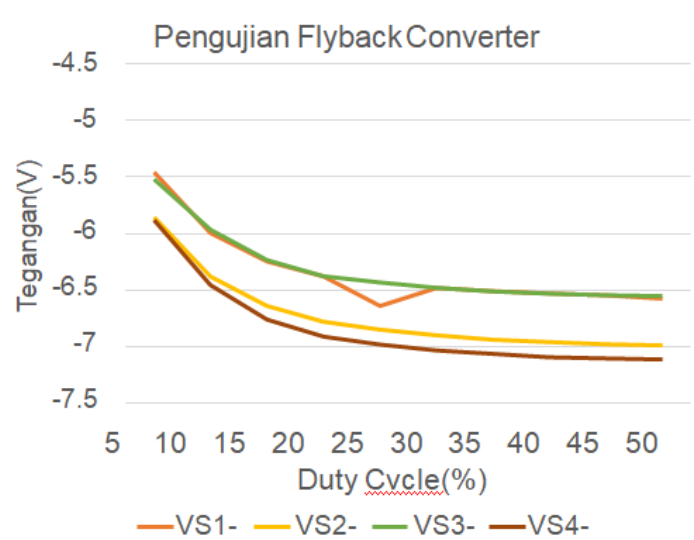

(b)

Gambar 9. Kinerja Flyback berdasarkan duty cycle: (a) Tegangan output positif dan (b) Tegangan output negatif 
Prototipe Power Supply Gate Driver untuk Multilevel Inverter dengan Menggunakan Flyback Converter Multi Output Novie Ayub Windarko, Akhmad Puryanto, Rachma Prilian Eviningsih, Moh. Zaenal Efendi, Eka Prasetyono, Bambang Sumantri

Pada Gambar 8 menunjukkan respon $V_{d s}$ MOSFET dengan time/div=5 ms/div dan V/div=10 v/div. Untuk Gambar 8 bawah adalah gambar atas yang diperbesar dengan time/div $=1 \mu \mathrm{s} /$ div. Pada Gambar 8 bawah bisa dilihat proses switching mosfet berubah dari kondisi dari on menuju off secara sempurna.

Pada Gambar 9 dapat dilihat bahwa tegangan keluaran flyback cenderung konstan pada saat duty cycle mencapai 30\%. Pada Gambar 9a pengujian output tegangan bias positif, semakin besar duty cycle nilai tegangan output flyback semakin besar secara linear. Namun pada saat duty cycle 30\% output teganganya relatif stabil dan tidak banyak mengalami perubahan. Untuk tegangan pada VS2+ memiliki sedikit perbedaan dibandingkan VS1+, VS3+, VS4+. Pada Gambar 9b juga menunjukkan hal yang sama, VS1menghasilkan tegangan bias negatif paling rendah. Hal ini disebabkan oleh lilitan kumparan yang tidak ideal.

\section{Kesimpulan}

Makalah ini menjelaskan tentang konverter flyback multioutput untuk menghasilkan tegangan bias positif dan negatif untuk suplai daya gate driver. Aplikasi dari konverter ini khususnya untuk suplai daya gate driver pada multilevel inverter yang membutuhkan banyak unit suplay daya untuk gate driver. Diharapkan desain ini dapat diaplikasikan dengan menggunakan komponen $S M D$ yang ukurannya cukup kecil sehingga konverter bisa lebih ringkas.

\section{Daftar Pustaka}

[1] M. Hagiwara, K. Nishimura, and H. Akagi, "A Medium-Voltage Motor Drive with A Modular Multilevel PWM Inverter," IEEE Trans. Power Electron., vol. 25, no. 7, pp. 1786 -1799 , Jul. 2010.

[2] E. Najafi and A. H. M Yatim, "Design and Implementation of A New Multilevel Inverter Topology," IEEE Transactions On Industrial Electronics, vol. 59, no. 11, pp. 4148-4154, 2011.

[3] F. Z. Peng, W. Qian, and D. Cao," Recent Advances in Multilevel Converter/Inverter Topologies and Applications," In Proc. IEEE 2010 International Power Electronics Conference-ECCE ASIA , pp. 492-501, June 2010.

[4] E. Babaei and S. S. Gowgani, "Hybrid Multilevel Inverter Using Switched Capacitor Units," IEEE Transactions on Industrial Electronics, vol. 61, no. 9, pp. 4614-4621, 2013.

[5] M. R. Banaei and S. Ebrahim, "New Multilevel Inverter with Reduction of Switches and Gate Driver," J. of Energy Conversion and Management, vol. 52, no. 2, pp. 1129-1136, 2011.

[6] M. Schweizer and J. W. Kolar, "Design and Implementation of a Highly Efficient ThreeLevel T-Type Converter for Low-Voltage Applications," IEEE Trans. Power Electron., vol. 28, no. 2, pp. 899-907, Feb. 2013.

[7] Y. Ye and K. E. Cheng, "Bootstrap Gate Driver and Output Filter of an SC-based Multilevel Inverter for Aircraft APU," In Proc. IEEE 6th International Conference on Power Electronics Systems and Applications (PESA), pp. 1-5, December 2015. 
[8] A. Stillwell and R. C. N. Pilawa-Podgurski, "A Five-Level Flying Capacitor Multilevel Converter With Integrated Auxiliary Power supply and Start-Up," IEEE Transactions on Power Electronics, vol. 34, no. 3, pp. 2900-2913, 2018.

[9] C. B. Barth, T. Foulkes, W. H. Chung, T. Modeer, P. Assem, Y. Lei, and R. C. PilawaPodgurski, "Design and Control of a GaN-based, 13-level, Flying Capacitor Multilevel Inverter," In Proc. IEEE 17th Workshop on Control and Modeling for Power Electronics (COMPEL), pp. 1-6, June 2016.

[10]Z. Liao, Y. Lei, and R. C Pilawa-Podgurski, "A GaN-based Flying-Capacitor Multilevel Boost Converter for High Step-Up Conversion," In Proc. IEEE Energy Conversion Congress and Exposition (ECCE, pp. 1-7), September 2016.

[11]Z. Ye, Y. Lei, W. Liu, P. S. Shenoy, and R. C. N. Pilawa-Podgurski, "Design and Implementation of a Low-Cost and Compact Floating Gate Drive Power Circuit for GaN-based Flying Capacitor Multi-level Converters,"In Proc. IEEE Applied Power Electronics Conference and Exposition (APEC), pp. 2925-2931, 2017.

[12]R. Zhao, D. Gladwin, X. Mou, and D. A. Stone, "A Non-Isolated Bipolar Gate Driver with Self-Driven Negative Bias Generator in High-Side-Only Application," In Proc. IECON 2018 - 44th Annual Conference of the IEEE Industrial Electronics Society, pp. 13621367, Oct 2018.

[13]M. A. B. Nugroho, N. A. Windarko, and B. Sumantri, "Perancangan Kendali Multilevel Inverter Satu Fasa Tiga Tingkat dengan PI+ Feedforward pada Beban Nonlinier," ELKOMIKA: Jurnal Teknik Energi Elektrik, Teknik Telekomunikasi, \& Teknik Elektronika, vol. 7, no. 3, pp. 493-507, 2019. 